2 Oomen KJ, Johnson PC, Ray CG. Herpes simplex type 2, virus encephalitis presenting as psychosis. Am J Med 1982;73:301-460.

3 Bakchine S, Chain F, Lhermitte F. Syndrome de Klüver-Bucy complet après une encéphalite à herpès de type 2. Rev Neurol (Paris) 1986;142:126-32.

4 Manz HJ, Phillips TM, McCullough DS. Herpes simplex type 2 encephalitis concurrent with known cerebral metastases. Acta Neuropathol 1979;47:233-40.

5 Tucker T, Dix RD, Davis RL et al. Myelitis with cytomegalovirus and multiple herpes viruses in the acquired immunodeficiency syndrome (AIDS). Neurology 1984;34(suppl 1):135.

6 Levy RM, Bredesen DE, Rosenblum ML. Opportunistic central nervous system pathology in patients with AIDS. Ann Neurol 1988;23(suppl):S7-S12.

\section{Creutzfeld-Jacob like syndrome due to lithium toxicity}

,Sir: Recently in this Journal Smith and Kocen reported on EEG abnormalities in - lithium neurotoxicity,' stating that periodic sharp waves have not been described in the EEG of patients with lithium intoxication. However, there exists literature since 1971 about this subject. ${ }^{23}$ Recently we described some patients. ${ }^{4}$

One of them was a 72 year old women with lithium intoxication (serum lithium level 2.3 $\mathrm{mmol} / \mathrm{l})$. The EEG showed periodic sharp waves, triphasic waves and diffuse slowing. These EEG abnormalities decreased the weeks thereafter.

CHARLES JF KEMPERMAN Dept of Psychiatry, State University Hospital, Groningen

The Netherlands PROF SLH NOTERMANS Dept of Clinical Neurophysiology, St Radboud Hospital, Nijmegen,

The Netherlands

\section{References}

1 Smith SJM, Kocen RS. A Creutzfeld-Jakob like syndrome due to lithium toxicity. $J$ Neurol Neurosurg Psychiatry 1988;51:120-3.

2 Helmchen H, Kanowski S. EEG-Veranderungen unter lithium-therapie. Nervenarzt 1971;42:144-8.

3 Itil TM, Akpinar S. Lithium effect on human electroencephalogram. Clin Electroencephalogr 1971;2:89-102.

4 Kemperman CJF, Rooy de J, Notermans SLH. The EEG plays a role in detecting and preventing lithium neurotoxicity. Clin Neurol Neurosurg 1987(suppl 1);89-2:147-8.

\section{Intracranial aneurysm and HLA-DR2}

Sir: We read with interest the letter from Schievink et al concerning HLA antigens and intracranial aneurysms. They commented on a study by Østergaard's group ${ }^{2}$ which provided some evidence in support of a genetic predisposition to intracranial aneurysms, namely an increased incidence of HLA-DR2 amongst aneurysm patients.

Dr Schievink and his colleagues could not substantiate this hypothesis when they analysed the frequency distribution of HLADR2 in a retrospective study of 31 cases of death associated with subarachnoid haemorrhage (SAH) following rupture of intracranial aneurysms. Quite correctly, they emphasise the selective nature of both Østergaard's data and their own and they point to the need for larger studies of unselected patients to include those with ruptured and unruptured aneurysms.

We fear that there will inevitably be some selection despite implementation of the above suggestions. Referral to neurosurgical centres of patients after SAH will depend upon local policy but in general neurosurgeons will only be notified of the fittest patients. Furthermore, even patients with unruptured aneurysms will have been selected in that of necessity they will present with symptoms which justify the use of angiography needed to demonstrate their aneurysms.

In the light of the foregoing, the results of an investigation recently completed by us may be of interest. We conducted a pilot study concerning the possible implication of HLA antigens in the pathogenesis of nonhaemorrhagic deterioration following aneurysml SAH. The results of this study, full publication of which is in preparation, were recently announced in a preliminary communication. ${ }^{3}$

Forty patients ( 28 females, 12 males) of mean age 44 years (SD 13.8) who had sustained an aneurysmal SAH were followed to death or discharge. Tissue typing was performed using standard methods. The table compares the frequency of HLA-DR2 amongst controls, the total SAH study population and patients grouped according

\begin{tabular}{lrl}
\hline Group & $n$ & $\% H L A-D R 2$ \\
\hline Control & 381 & $28 \cdot 8$ \\
SAH group & 38 & $28 \cdot 9$ \\
ACoA & 17 & $41 \cdot 2$ \\
MCA & 11 & $36 \cdot 4$
\end{tabular}

ACoA-anterior communicating artery aneurysm; MCA-middle cerebral artery aneurysm. The incidence of multiple aneurysms $(20 \%)$ or aneurysms at other sites was too small for valid comparison. to aneurysm site. Technical difficulties precluded typing for HLA-DR2 in two patients (one male and one female). No statistical significance could be observed between the several groups (chi square with Yates's correction).

On the basis of the above, we agree with Schievink et al that the overall frequency of HLA-DR2 does not differ significantly between control groups and the aneurysmal SAH population. However, the slightly higher incidence of HLA-DR2 in those patients with anterior communicating artery aneurysms suggests that a weak genetic predisposition for the development of this type of aneurysm may exist.

RICHARD H LYE University of Manchester, Department of Neurosurgery, Manchester Royal Infirmary, Manchester M13 9WL. PA DYER North West Regional Tissue Typing Laboratory, St. Mary's Hospital, Manchester, UK

\section{References}

1 Schievink WI, De Waal LP, Hageman LM, et $a l$. Intracranial aneurysm and HLA-DR2. $J$ Neurol Neurosurg Psychiaty 1988;51:883.

2 Østergaard JR, Bruun-Petersen G, Lamm LU. HLA antigens and complement types in patients with intracranial sacular aneurysms. Tissue Antigens 1986;28:176-81.

3 Lye RH, Sheldon S, Brown D, et al. HLA antigens and subarachnoid haemorrhage. $J$ Neurol Neurosurg Psychiaty 1988;51:465-6.

\section{An implant clamp for atlanto-axial fusion}

Sir: Mills et al, in a letter to the Journal' describe an implant clamp for the surgical stabilisation of $\mathrm{Cl}-\mathrm{C} 2$ instability. The clamp is a unique device and obviously appears to render substantial stability to the spine. We, however, have several concerns regarding the utilisation of such a device. First, the Brooks and Gallie fusions, as mentioned by Mills et al, are widely accepted. They, in addition, have a low complication rate and an acceptable fusion rate. Furthermore, the sublaminar wires used with these fusions offer a minimal risk of spinal cord compression because of the small volume occupied by these wires in the capacious upper cervical spinal canal. On the other hand, the photographs accompanying the letter by Mills, et al, demonstrate a rather bulky device. The hooks of this device appear to be 
significantly compromising the dorsal spinal canal at the $\mathrm{Cl}$ level.

If the clinical situation dictates a need for such a device for internal fixation, the Halifax interlaminar clamps have a proven safe and efficacious track record. ${ }^{2}$ Cybulski et al, have demonstrated their usefulness for $\mathrm{C} 1-\mathrm{C} 2$ instability. Furthermore, the Halifax clamps appear to cause less encroachment on the spinal canal (compare the lateral radiographs in Mills, et al, and Cybulski, ${ }^{3}$ et al.

Although the described device may have appropriate applications, we caution its widespread use.

EDWAR' C BENZEL, LEE KESTERSON

School of Medicine in Shreveport

Louisiana State University Medical Center 1501 Kings Highway

Post Office Box 33932

Shreveport, LA 71130-3932

\section{References}

1 Mills KLG, Scotland TR, Wardlow D, Wytch R. An implant clamp for atlanto-axial fusion. J Neurol Neurosurg Psychiatry 1988;51: 450-1

2 Holness RO, Huestis WS, Howes WJ, Langille RA: Posterior stabilization with an interlaminar clamp in cervical injuries: Technical note and review of the long term experience with the method. Neurosurg 1984;14:318-322.

3 Cybulski GR, Stone UL, Crowell RM, Rifai MHS, Gandhi Y, Glick R: Use of Halifax interlaminar clamps for posterior $\mathrm{Cl}-\mathrm{C} 2$ arthrodesis. Neurosurg 1988;22:429-31.

The frequency, characteristics and prognosis of epileptic seizures at the onset of stroke

Sir: The occurrence of epileptic seizures prior to or at the onset of stroke has recently been reassessed in two reports by Shinton et al. ${ }^{12}$ Both investigations (which are based on the same group of patients) seem to support the case that cerebrovascular disease can be implicated not only in seizures occurring in the acute stage of the stroke but also prior to it. While the first point is well established, the problem of epilepsy preceding stroke deserves some further comments.

Firstly, in both reports the diagnosis of ischaemic and haemorrhagic strokes was mainly based on a scoring system, CT find- ings being available only in a minority of cases. This could be relevant to the actual incidence of seizures prior to haemorrhagic stroke since, apart from case no 2 of Shinton et $a l^{2}$ only three cases of heralding epilepsy related to a primary intracerebral haemorrhage (PIH) have so far been recorded. ${ }^{3}$

Secondly, the existence of a "vascular precursor epilepsy", ${ }^{3}$ as reported over the last decades, ${ }^{4}$ is not universally accepted, ${ }^{56}$ particularly when epilepsy and stroke are obviously unrelated (for instance case nos 4 and 7 of Shinton et $a l^{\prime}$ ).

Thirdly, even a retrospective case-control investigation can be affected by several potential sources of bias, as pointed out by Starkey and Warlow.'

In an unpublished series of 82 consecutive cases of PIH confirmed by CT, we have never found seizures preceding the stroke, while in $6.7 \%$ of patients with angiographically proved carotid occlusive disease, epileptic seizures were the presenting symptom. ${ }^{89}$

The pathophysiology of the rare (if any) epileptic seizures heralding PIH is hard to explain. On the contrary, an aetiological relationship between cerebral ischaemia and epilepsy could be accounted for by at least two pathophysiological mechanisms. In fact seizures may arise from small clinically silent infarctions, ${ }^{10}$ thus being not basically different from seizures occurring as a sequel of ischaemic stroke; ${ }^{4}$ or as a direct consequence of "low-grade" cerebral ischaemia, as suggested by some neurophysiological evidence. " The latter hypothesis has been challenged by Yanagihara et $a l^{12}$ who demonstrated that epileptic movements of extremities resulting from transient haemodynamic ischaemic episodes are associated with slow waves over the contralateral hemisphere, thus suggesting a release phenomenon of subcortical structures. $^{13}$ Actually, transient cerebral ischaemia could be responsible either for release or epileptic phenomena, at least in principle. ${ }^{4}$

The availability of high resolution neuroimaging techniques can provide guidelines for a more factual approach to the whole matter. A protocol for a prospective study should be worked out, to investigate patients who had their first epileptic seizure after the age of $40 \mathrm{yrs},{ }^{10}$ with no detectable lesions at CT and MRI at the time, separately considering partial and generalised epilepsy. The risk factors for a cerebrovascular accident should be investigated as well, although their relevance to late onset epilepsy has recently been challenged (Neufeld $e t$ al, Abstracts of 17th International Epilepsy Congress, 1987:85). If follow-up indicates that ischaemic strokes occur more frequently in either group than in a matched populatigh, this could be regarded as proof that seizuzs may sometimes reveal an otherwise clinically silent cerebral ischaemic disease añd therefore herald a major cerebrovascutar event. By the same token, epileptic seizuxes could be included among the possible masifestations of TIAs, as already suggested.

LEONARDO COCF

EMILIO FAVA世E LIZIA REA I

Department of Neurology, University of Geno要, 16132 Genova, It

\section{References}

1 Shinton RA, Gill JS, Zezulka AV, Beevers D'G The frequency of epilepsy preceding strotes. Case-control study in 230 patients. Lanicet 1987;i:11-3,

2 Shinton RA, Gill JS, Melnick SC, Gupta Ađ, Beevers DG. The frequency, characteristects and prognosis of epileptic seizures at onset of stroke. $J$ Neurol Neurosurg PSy chiatry 1988:51:273-6.

3 Barolin GS, Scherzer GS, Schnaberth iG. Epileptische Manifestationen als Vorboiren von Schlaganfällen: "Vaskulare PräkgrsôEpilepsie" Fortschr Neurol Ps 1971;39:199-216.

1971;39:199-216.
4 Favale E. Cerebral ischemia as a ca政e $\frac{O}{-}$ of epileptic seizures. In: Loeb C, ed. Studies in Cerebrovascular Disease. Milano: Mass $\mathbb{B}^{\mathrm{h}}$ Italia, 1981:121-40.

5 De Carolis P, D'Alessandro R, Ferraca Andreoli A, Sacquegna T, Lugaresi E $\mathrm{K}_{\mathrm{L}} \mathrm{Ale}$ seizures in patients with internal carota and middle cerebral artery occlusive diseaseffedowing ischemic events. J Neurol Neuros Psychiatry 1984;47:1345-7.

6 Frisher S, Herishanu YO. Frequency If epilepsy preceding stroke. Lancet 1987;ii:3多.

7 Starkey IR, Warlow CP. Epilepsy preced stroke. Lancet 1987;i:742-3.

8 Cocito L, Favale E, Reni L. Epileptic seizure on cerebral arterial occlusive disease. Stroge 1982;13:189-95.

9 Cocito L, Favale E, Reni L. Epileptic seizuresön patients with cerebral arterial occlusive disease. Stroke 1983;14:305-6.

10 Shorvon SD, Gilliatt RW, Cox TC, Yu Y Evidence of vascular disease from CT scainning in late-onset epilepsy. $J$ Neuñ $l$ Neurosurg Psychiaty 1984;47:225-30.

11 Heiss W-D, Hayakawa T, Waltz AG. Cortiè function during ischemia. Arch Neum 1976;33:813-20.

12 Yanagihara T, Piepgras DG, Klass DW Repetitive involuntary movement associated with episodic cerebral ischemia. Ann NeuOl 1985;18:244-50.

13 Gastaut H, Behrend RCh. Die klinische utod elektroencephalographische Differenti: diagnostik der fokalen und generalisiert epileptischen und ischämischen Anfälle. $A$ ơ Neurovegetativa (Wien) 1961;23:137-53. 